\title{
Effects of 12-week resistance exercise and interval training on the skeletal muscle area, physical fitness, and mental health in old women
}

\author{
Jae-Ryang Yoon', Gi-Chul Ha', Seol-Jung Kang ${ }^{2}$, Kwang-Jun Ko,** \\ 'Department of Physical Education, Korea National Sport University, Seoul, Korea \\ ${ }^{2}$ Department of Physical Education, Changwon National University, Changwon, Korea \\ ${ }^{3}$ Department of Sports Medicine, National Fitness Center, Seoul, Korea
}

This study aimed to determine the effects of resistance exercise and interval training on the visceral fat to skeletal muscle area, physical fitness, cognitive functions, and mental health in old women. The study was conducted among 30 older women enrolled in the National Fitness Center in Seoul. They were randomly sampled into the resistance exercise and interval training group (RI group: $n=10$, aged $64.10 \pm 3.35$ ), the resistance and aerobic exercise group (RA group: $n=10$, aged $65.20 \pm$ 5.10 ), and the control group ( $n=10$, aged $63.20 \pm 2.62$ ). Twelve weeks of exercise involving 30 -min resistance exercise followed by 30-min interval training or aerobic exercise, 3 times a week, were performed by each group. A computed topography was used to the measure visceral fat area and the thigh skeletal muscle area. For physical fitness, maximum oxygen uptake, knee isokinetics muscle functions, ankle range of motion, and functional fitness of the elderly (muscle strength, cardiorespiratory endurance, flexibility, balance, and agility) were measured.
For blood test, the metabolic syndrome risk factors, growth hormone, testosterone, and insulin-like growth factor-1 (IGF-1) were measured. A self-administered questionnaire was used to measure cognitive functions and quality of sleep. The 12-week RA and RI groups were effective in changing the thigh skeletal muscle area, IGF-1, knee joint extension and flexion, ankle range of motion, functional fitness, and quality of sleep. In conclusion, resistance exercise, followed by interval training or aerobic exercise, was effective in improving the skeletal muscle function indexes, physical fitness, and quality of sleep for the elderly. However, no difference was found between the two types of exercise.

Keywords: Elderly women, Resistance exercise and interval training, Visceral fat/skeletal muscle area, Physical fitness, Cognitive function, Quality of sleep

\section{INTRODUCTION}

The recent socio-demographic characteristics have included life expectancy adjusted to aging and disability on the basis of the extended average life expectancy. In an aging society, importance is attached to disability-adjusted life expectancy without chronic disease or dysfunction (Rowe and Kahn, 1997). However, sarcopenia, caused by a decrease in skeletal muscle mass and muscle strength, plays a central role in shortening disability-adjusted life expectancy in old age (Nair, 2005) due to aging reducing growth hormone and insulin-like growth factor 1 (IGF-1), both of which affect the anabolism of muscle protein metabolism (Møller et al., 2007). Moreover, old age is characterized by the decrease in functional fitness, which makes it hard for one to independently perform physical activity, tending to cause physical disorder (Enoki et al., 2007; Janssen et al., 2002).

Old age can also involve cognitive impairment directly associated with the quality of life. Cognitive impairment was associated with the activities of daily living in the elderly population (Haimov et al., 2008; Luck et al., 2010). Another mental health problem in old age is sleep disturbance. While sleep disturbance can occur in every age group, it is more common in the elderly group.

\footnotetext{
*Corresponding author: Kwang-Jun Ko (D) https://orcid.org/0000-0002-2474-5600 Department of Sports Medicine, National Fitness Center, 424 Olympic-ro, Songpa-gu, Seoul 05540, Korea

E-mail: tigerkor80@naver.com

Received: October 22, 2019 / Accepted: November 21, 2019
}

This is an Open Access article distributed under the terms of the Creative Commons Attribution Non-Commercial License (http://creativecommons.org/licenses/by-nc/4.0/) which permits unrestricted non-commercial use, distribution, and reproduction in any medium, provided the original work is properly cited. 
Some epidemiological studies found that in the United States, $\geq 50 \%$ of the elderly complained of sleep disturbance (Foley et al., 1995) and that the sleep problems led to a decline in the ability to maintain sleep rather than changes in the absolute sleep demand (Crowley et al., 2011). It is therefore necessary to develop intervention strategies for the diverse physical and mental health problems transpiring in old age.

Exercise is effective in improving physical and cognitive functions, as well as quality of sleep (Cassilhas et al., 2007; Misic et al., 2007). Many researchers found that resistance exercise was effective in increasing skeletal muscle mass, in synthesizing muscle protein, and in improving the muscle functions in the elderly population (Koopman et al., 2009; Rolland et al., 2008; Strasser et al., 2009). The muscle function increase caused by resistance exercise improved functional fitness (Liu and Latham, 2009; Ramírez-Campillo et al., 2014). Aerobic exercise is effective in improving the cardiopulmonary functions and in increasing skeletal muscle oxidation capacity (Hagberg et al., 1989; Short et al., 2004). Recent research has reported that interval training, which involves repeated performance of high- and low-intensity exercise helpful for the cardiopulmonary functions, was also applied to cardiac rehabilitation programs and was effective in recovering the motor skills and the cardiovascular functions (Milanović et al., 2015; Rognmo et al., 2004; Weston et al., 2014). Many researchers found that in old age, interval training was also effective in protein synthesis, which is considered important in developing the muscle functions (Bell et al., 2015; Gibala et al., 2013; Robinson et al., 2017).

However, almost no comparative analysis has been performed on physical and mental health between conventional types of resistance interval training (RIT) and resistance aerobic exercise (RAE), in pursuit of health promotion for the elderly. This study intended to allow old women to perform RIT and RAE for 12 weeks and to determine which combination was more effective in improving the visceral fat to skeletal muscle area ratio, physical fitness, cognitive functions, and quality of sleep.

\section{MATERIALS AND METHODS}

\section{Subjects}

This study was conducted among 30 physically healthy old women enrolled in the National Fitness Center in Seoul. They were divided into the resistance exercise and interval training group (RI group, $\mathrm{n}=10$ ), the resistance exercise and aerobic exercise group (RA group, $n=10)$, and the control group $(n=10)$. Before the experiment, the subjects were given explanation about the purpose and methods of this study and were asked to give consent. The exclusion criteria for sampling included surgical history and medication due to cancer diagnosis, cardiovascular disease, pulmonary disease, and musculoskeletal disorder. This study was reviewed by Korea National Sport University's Institutional Review Board (1263-201809-BR-007-02). The participants' physical characteristics are presented in Table 1.

\section{Measurement items and methods}

The subjects' height and weight were measured using an automatic body meter (Jenix, Seoul, Korea). The body mass index (BMI) was calculated by dividing the measured body weight $(\mathrm{kg})$ by the square $\left(\mathrm{m}^{2}\right)$ of the height $(\mathrm{cm})$. The body fat percentage was estimated using bioelectrical impedance analysis (InBody 3.0, InBody, Seoul, Korea). Computed topography (CT; Siemens, Somato Emotion, Oberasbach, Germany) was employed to determine the total abdominal fat area, the visceral fat area, the subcutaneous fat area, and the thigh skeletal muscle area. The visceral to subcutaneous fat ratio and the visceral fat to skeletal muscle area ratio were also estimated.

An automatic blood pressure monitor (FT500R, Jawon Medical, Seoul, Korea) was utilized to measure blood pressure. The subjects took a 5-min rest in a chair and, subsequently placing their right forearm into the instrument to register two measurements, the mean of which was used. Approximately 100-mL blood collected from a brachial vein $10 \mathrm{hr}$ after a meal was tested using a biochemical analyzer (Selecta XL, Vital Scientific, Newton, MA, USA). The

Table 1. Physical characteristics of subjects

\begin{tabular}{lccccc}
\hline Group & Age $(\mathrm{yr})$ & Height $(\mathrm{cm})$ & Weight $(\mathrm{kg})$ & BMl $\left(\mathrm{kg} / \mathrm{m}^{2}\right)$ & Body fat $(\%)$ \\
\hline $\mathrm{RI}(\mathrm{n}=10)$ & $64.10 \pm 3.35$ & $159.11 \pm 5.08$ & $58.66 \pm 6.90$ & $23.11 \pm 1.69$ & $31.87 \pm 3.73$ \\
$\mathrm{RA}(\mathrm{n}=10)$ & $65.20 \pm 5.10$ & $154.26 \pm 4.18$ & $53.13 \pm 3.85$ & $22.34 \pm 1.67$ & $30.49 \pm 2.73$ \\
Control $(\mathrm{n}=10)$ & $63.20 \pm 2.62$ & $159.01 \pm 4.39$ & $56.56 \pm 7.81$ & $22.32 \pm 2.41$ & $30.43 \pm 4.23$ \\
P-value & 0.513 & 0.038 & 0.170 & 0.593 & 0.608 \\
\hline
\end{tabular}

Values are presented as mean \pm standard deviation.

$\mathrm{Rl}$, resistance and interval training; $\mathrm{RA}$, resistance and aerobic exercise; BMl, body mass index. 
blood test covered total cholesterol, high-density lipoprotein cholesterol, low-density lipoprotein cholesterol, triglyceride, fasting blood glucose, growth hormone, testosterone, and IGF-1.

Exercise stress test was performed by means of an automatic breathing gas analyzer (Q4500, Quinton, Bothell, WA, UAS) with an altered Balke protocol on a treadmill. The test was discontinued when the rating of perceived exertion is $\geq 17$, the respiratory exchange ratio $\geq 1.15$, the maximum heart rate $\geq 90 \%$ (220-age), and when the subject demands for discontinuation. The knee isokinetics muscle function test was performed using an isokinetic equipment, Biodex system-3 (Biodex Co., New York, NY, USA). For load velocity, right and left power measurements per weight were repeated 3 times, with angular velocity set at $60^{\circ} / \mathrm{sec}$. For the ankle range of motion, a goniometer (Goniometers, Sammons Preston, Bolingbrook, IL, USA) was used, with the anatomical posture of $0^{\circ}$ as a starting posture. Dorsal and plantar flexions of the ankle joints were performed, with the knee joints flexed.

For functional fitness related to daily life for the elderly, muscle strength (grip strength, arm curl, chair stand), cardiorespiratory endurance (2-min step), flexibility (chair \& sit reach, back scratch), balance (functional reach, one-leg stance), and agility (2.45-m upand-go) were tested. Grip strength was tested twice with both hands alternatively using a grip dynamometer (GRIP-D 5101, TAKEI, Tokyo, Japan). For arm strength test (arm curl), a set of lifting and lowering a 2-kg dumbbell in a sitting position was counted for 30 sec. For leg strength test (chair stand), the subjects were asked to repeatedly sit down on and stand up from a chair for $30 \mathrm{sec}$. For cardiorespiratory endurance test, the subjects were asked to do a 2-min step. While doing a 2-min step, they were asked to lift each of the legs to the marked height and to lower it so that it could land completely on the ground. For lower limb flexibility test (chair $\&$ sit reach), the subjects were asked to have a leg stretched and both hands reached out toward the tip of the foot on a chair with the aim of measuring the gap between the hands and the tip of the foot. For upper limb flexibility test (back scratch), they were asked to lift the targeted hand above the shoulder and the other hand above the middle of the back so that the hands reached for each other with the aim of measuring the gap between the middle fingers. For balance test, functional reach and one-leg stance with eyes closed were tested. For functional reach test, subjects were asked to stand straight and reach the arms parallel to each other with the shoulder joints flexed to $90^{\circ}$, with the aim of measuring the distance between the tip of the third phalanges distalum in the starting position and in the greatest reach. For one-leg stance with eyes closed, people were asked to stand on a single leg akim- bo. For agility test was 2.45 -m up-and-go measured. With a starting signal, they were asked to stand up from a chair and walk at a rapid pace around a cone at 2.45 -m distance and return to sit down on the chair with the aim of measuring the length of time between the signal and the return on the chair.

For cognitive dysfunction test, the Korean Dementia Screening Questionnaire-Cognition (KDSQ-C) developed by Yang et al. (2002) was tapped. This tool is composed of three areas: memory, linguistic competence, and activities of daily living. The score for each area ranges from 0 to 2, with the total score being 30 and with $\geq 6$ suspected as cognitive dysfunction. For reliability based on internal consistency, Cronbach $\alpha$ was estimated at 0.78 at the time of its development and at 0.65 in this study.

The Korean translation by Sohn et al. (2012) of the Pittsburgh Sleep Quality Index (PSQI) developed by Buysse et al. (1989) was used to measure the quality of sleep. PSQI is composed of seven areas: perceived quality of sleep, sleep latency, sleep duration, usual sleep efficiency, sleep disturbance, sleeping medication use, and daytime dysfunction. The score for each area ranges from 0 to 3 and the total score was 0-21 for the sum of the seven items, with the higher total score meaning a lower quality of sleep. For reliability based on internal consistency, Cronbach $\alpha$ was estimated at 0.83 at the time of its development and at 0.67 in this study.

\section{Exercise program}

The exercise program was run 3 times a week for 12 weeks after a week of exercise intensity setting, education about how to do resistance exercise and aerobic exercise, and exercise adjustment. Resistance exercise intensity was determined using one-repetition maximum $(1-\mathrm{RM})$ indirect measurement $\left[1-\mathrm{RM}=\mathrm{W}_{0}+\mathrm{W} 1,\left(\mathrm{~W}_{0}=\right.\right.$ weight permitting 7-8 sets of shrinking), W1 $=$ Wo $\times 0.025 \times \mathrm{R}$ (number of repeats)] developed by Fleck et al. (1988). For aerobic exercise intensity, Karvonen's (1957) formula [target heart beat = exercise intensity $\times$ (maximum heart beat - heart beat at rest $)+$ heart beat at rest] was used to set a target heartbeat.

The RA group was asked to ride a bicycle (for $30 \mathrm{~min}$ ) after a 30-min resistance exercise. The RI group was asked to do interval training for $30 \mathrm{~min}$ after a 30-min resistance exercise. Every group was asked to do warming-up before exercise and to execute 5-min walking and 5-min stretching for cooling-down. The details of resistance exercise, aerobic exercise, and interval training are as follows.

For resistance exercise, the subjects were asked to use weights to perform a total of nine events (five for the upper part of the body [chest press, lateral pull down, arm curl, back extension, and 
Yoon JR, et al. • Effects of 12-week resistance and interval training

Table 2. Change in body composition and computed tomography scan measurement

\begin{tabular}{|c|c|c|c|c|c|c|c|c|c|}
\hline \multirow{2}{*}{ Variable } & \multicolumn{2}{|c|}{ Rl group } & \multicolumn{2}{|c|}{ RA group } & \multicolumn{2}{|c|}{ Control group } & \multicolumn{3}{|c|}{$P$-value } \\
\hline & Pre & Post & Pre & Post & Pre & Post & Group & Time & Interaction \\
\hline \multicolumn{10}{|l|}{ Body composition } \\
\hline Weight (kg) & $58.66 \pm 6.90$ & $58.70 \pm 7.65$ & $53.13 \pm 3.85$ & $53.79 \pm 3.78$ & $56.56 \pm 7.81$ & $57.44 \pm 7.95$ & 0.209 & 0.038 & 0.353 \\
\hline $\mathrm{BMI}\left(\mathrm{kg} / \mathrm{m}^{2}\right)$ & $23.11 \pm 1.69$ & $23.07 \pm 2.08$ & $22.34 \pm 1.67$ & $22.64 \pm 1.53$ & $22.32 \pm 2.41$ & $22.60 \pm 2.38$ & 0.725 & 0.105 & 0.362 \\
\hline Body fat $(\%)$ & $31.87 \pm 3.73$ & $31.88 \pm 3.69$ & $30.49 \pm 2.73$ & $30.82 \pm 3.04$ & $30.43 \pm 4.23$ & $30.96 \pm 4.21$ & 0.695 & 0.128 & 0.519 \\
\hline \multicolumn{10}{|l|}{ CT scan measurement } \\
\hline TFA $\left(\mathrm{cm}^{2}\right)$ & $434.16 \pm 64.93$ & $434.76 \pm 89.58$ & $422.60 \pm 50.14$ & $420.94 \pm 47.96$ & $414.96 \pm 67.83$ & $418.77 \pm 66.77$ & 0.811 & 0.907 & 0.960 \\
\hline Subcutaneous $\left(\mathrm{cm}^{2}\right)$ & $246.99 \pm 57.09$ & $245.22 \pm 62.61$ & $217.29 \pm 27.64$ & $210.34 \pm 28.77$ & $228.03 \pm 49.02$ & $221.57 \pm 48.31$ & 0.274 & 0.403 & 0.926 \\
\hline Visceral $\left(\mathrm{cm}^{2}\right)$ & $187.17 \pm 22.48$ & $189.54 \pm 33.75$ & $205.31 \pm 39.01$ & $206.81 \pm 35.59$ & $186.93 \pm 34.78$ & $193.14 \pm 31.84$ & 0.400 & 0.373 & 0.859 \\
\hline VSR & $0.43 \pm 0.58$ & $0.44 \pm 0.41$ & $0.47 \pm 0.60$ & $0.48 \pm 0.51$ & $0.45 \pm 0.71$ & $0.46 \pm 0.52$ & 0.197 & 0.115 & 0.780 \\
\hline Skeletal muscle area $\left(\mathrm{cm}^{2}\right)$ & $106.47 \pm 16.65$ & $117.38 \pm 18.36$ & $106.24 \pm 14.54$ & $113.43 \pm 15.21$ & $106.30 \pm 14.42$ & $107.29 \pm 14.83$ & 0.751 & 0.000 & 0.002 \\
\hline VMR & $1.79 \pm 0.27$ & $1.64 \pm 0.37$ & $1.94 \pm 0.27$ & $1.85 \pm 0.38$ & $1.76 \pm 0.24$ & $1.81 \pm 0.26$ & 0.402 & 0.123 & 0.114 \\
\hline
\end{tabular}

Values are presented as mean \pm standard deviation.

$\mathrm{Rl}$, resistance and interval; RA, resistance and aerobic; BMI, body mass index; TFA, total fat area; VSR, visceral to subcutaneous ratio; VMR, visceral fat to skeletal muscle area ratio.

crunch] and four for the lower part of the body [leg press, leg extension, leg curl, and heel raise]) for $30 \mathrm{~min}$. It was repeated 8-15 times at the intensity of $1-\mathrm{RM}, 60 \%-80 \%$, in 3 sets. For aerobic exercise, they were asked to do stationary bicycle exercise for 30 $\mathrm{mi}$ at the target heartbeat of 50\%-60\%. For interval training, they were asked to do stationary bicycle exercise for $5 \mathrm{~min}$ at the target heartbeat of $40 \%$, followed by 10 sets of a 30-sec bicycle ride at the target heartbeat of $80 \%-90 \%$ and a 90 -sec bicycle ride at the target heartbeat of $50 \%-60 \%$ for $20 \mathrm{~min}$. After interval training, they were asked to ride a bike for $5 \mathrm{~min}$ at the target heartbeat of $40 \%$. They wore a Polar Heart Rate Analyzer (Polar Electro OY, Kempele, Finland) to maintain the exercise intensity, with the aim of confirming that they did aerobic exercise within the scope of the established target heartbeat.

\section{Data analysis}

The data were processed using IBM SPSS ver. 18.0 (IBM Co., Armonk, NY, USA) to estimate and diagram the mean and standard deviation for each area. Repeated-measure two-way analysis of variance was carried out for intergroup differences in the mean. The significance level $(\alpha)$ was set at 0.05 .

\section{RESULTS}

\section{Changes in body composition and CT findings}

The changes of body composition and the CT findings by exercise type are presented in Table 2. The RI group, the RA group, and the control group all had their weight significantly increased in the posttest $(P<0.05)$ but no interaction effect was found. No significant intergroup difference was found in BMI or the body fat percentage at each point of time. No interaction effect was found as well. The visceral fat area, the subcutaneous fat area, or the visceral to subcutaneous fat area ratio differed insignificantly among the groups at each point of time. All groups had their skeletal muscle area increased in the posttest $(P<0.001)$ and interaction effects were found $(P<0.01)$. The visceral fat to skeletal muscle area ratio differed insignificantly.

\section{Changes in metabolic syndrome risk factors and hormone}

The changes in the metabolic syndrome risk factors and hormone by exercise type are presented in Table 3. Systolic blood pressure, diastolic blood pressures, triglyceride, high-density lipoprotein cholesterol, low-density lipoprotein cholesterol, or fasting blood glucose are among the metabolic syndrome risk factors differing insignificantly among the groups at each point of time where no interaction effect was found. The growth hormone or testosterone differed insignificantly among the groups at each point of time. No interaction effect was found. All three groups had their IGF-1 increased in the posttest $(P<0.05)$ and no interaction effect was found.

\section{Changes in $\mathrm{VO}_{2 \max }$, knee isokinetic muscle function, and ankle range of motion}

The changes in maximum oxygen uptake $\left(\mathrm{VO}_{2 \max }\right)$ and the knee isokinetic muscle functions by exercise type are presented in Table 4 . $\mathrm{VO}_{2 \max }$ differed insignificantly among the groups at each point of 
Table 3. Change in metabolic syndrome risk factors and hormone

\begin{tabular}{|c|c|c|c|c|c|c|c|c|c|}
\hline \multirow{2}{*}{ Variable } & \multicolumn{2}{|c|}{ Rl group } & \multicolumn{2}{|c|}{ RA group } & \multicolumn{2}{|c|}{ Control group } & \multicolumn{3}{|c|}{$P$-value } \\
\hline & Pre & Post & Pre & Post & Pre & Post & Group & Time & Interaction \\
\hline $\mathrm{SBP}(\mathrm{mmHg})$ & $122.90 \pm 16.60$ & $119.70 \pm 13.64$ & $123.60 \pm 14.13$ & $118.10 \pm 14.73$ & $125.90 \pm 15.24$ & $126.90 \pm 16.22$ & 0.641 & 0.113 & 0.247 \\
\hline $\mathrm{DBP}(\mathrm{mmHg})$ & $75.10 \pm 12.97$ & $74.20 \pm 12.79$ & $74.70 \pm 10.95$ & $72.00 \pm 9.73$ & $76.70 \pm 9.68$ & $77.80 \pm 10.67$ & 0.697 & 0.596 & 0.613 \\
\hline $\mathrm{TG}(\mathrm{mg} / \mathrm{dL})$ & $93.60 \pm 29.02$ & $91.30 \pm 27.13$ & $102.30 \pm 65.02$ & $102.50 \pm 56.20$ & $72.00 \pm 27.93$ & $68.90 \pm 32.89$ & 0.195 & 0.773 & 0.972 \\
\hline $\mathrm{HDL}-\mathrm{C}(\mathrm{mg} / \mathrm{dL})$ & $61.10 \pm 12.37$ & $54.40 \pm 11.72$ & $60.80 \pm 10.40$ & $61.60 \pm 14.84$ & $65.60 \pm 11.43$ & $61.00 \pm 10.72$ & 0.515 & 0.084 & 0.286 \\
\hline LDL-C (mg/dL) & $132.30 \pm 44.91$ & $116.90 \pm 25.63$ & $104.10 \pm 24.11$ & $104.50 \pm 28.95$ & $111.90 \pm 26.73$ & $115.50 \pm 17.28$ & 0.196 & 0.520 & 0.376 \\
\hline FBG (mg/dL) & $93.70 \pm 6.68$ & $91.90 \pm 8.60$ & $94.40 \pm 5.62$ & $92.40 \pm 16.59$ & $97.70 \pm 13.94$ & $97.50 \pm 7.20$ & 0.265 & 0.649 & 0.962 \\
\hline $\mathrm{GH}(\mathrm{ng} / \mathrm{mL})$ & $1.54 \pm 1.38$ & $1.44 \pm 1.94$ & $1.34 \pm 0.57$ & $1.15 \pm 0.93$ & $1.46 \pm 1.15$ & $1.16 \pm 0.78$ & 0.869 & 0.334 & 0.917 \\
\hline IGF-1 (ng/mL) & $132.40 \pm 28.43$ & $157.28 \pm 40.81$ & $127.71 \pm 25.54$ & $136.60 \pm 20.19$ & $130.27 \pm 20.79$ & $135.00 \pm 30.50$ & 0.454 & 0.014 & 0.226 \\
\hline Testosterone (ng/dL) & $0.08 \pm 0.07$ & $0.14 \pm 0.16$ & $0.17 \pm 0.28$ & $0.17 \pm 0.06$ & $0.10 \pm 0.09$ & $0.10 \pm 0.07$ & 0.345 & 0.497 & 0.762 \\
\hline
\end{tabular}

Values are presented as mean \pm standard deviation.

RI, resistance and interval; RA, resistance and aerobic; SBP, systolic blood pressure; DBP, diastolic blood pressure; HDL-C, high-density lipoprotein cholesterol; LDL-C, low-density lipoprotein cholesterol; TG, triglyceride; FBG, fasting blood glucose; GH, growth hormone; IGF-1, insulin-like growth factor-1.

Table 4. Change in cardiorespiratory fitness, knee isokinetic function, and range of motion in foot joint

\begin{tabular}{|c|c|c|c|c|c|c|c|c|c|}
\hline \multirow{2}{*}{ Variable } & \multicolumn{2}{|c|}{ Rl group } & \multicolumn{2}{|c|}{ RA group } & \multicolumn{2}{|c|}{ Control group } & \multicolumn{3}{|c|}{$P$-value } \\
\hline & Pre & Post & Pre & Post & Pre & Post & group & time & Interaction \\
\hline $\mathrm{VO}_{2 \max }(\mathrm{mL} / \mathrm{kg} / \mathrm{min})$ & $26.10 \pm 8.59$ & $27.09 \pm 7.02$ & $27.95 \pm 4.91$ & $27.43 \pm 6.90$ & $27.09 \pm 6.41$ & $27.38 \pm 5.53$ & 0.917 & 0.824 & 0.862 \\
\hline Rt Knee EX TQ/BW (Nm) & $154.59 \pm 46.98$ & $182.85 \pm 48.29$ & $156.78 \pm 33.71$ & $181.93 \pm 32.80$ & $166.27 \pm 47.57$ & $163.64 \pm 47.45$ & 0.969 & 0.000 & 0.000 \\
\hline Lt Knee EX TQ/BW (Nm) & $150.74 \pm 49.38$ & $180.40 \pm 45.99$ & $161.51 \pm 30.40$ & $179.20 \pm 35.16$ & $162.20 \pm 44.55$ & $162.70 \pm 41.91$ & 0.911 & 0.000 & 0.000 \\
\hline Rt Knee FX TQ/BW (Nm) & $69.15 \pm 21.25$ & $84.31 \pm 21.19$ & $69.24 \pm 15.65$ & $79.39 \pm 12.55$ & $67.91 \pm 11.86$ & $64.20 \pm 18.68$ & 0.309 & 0.006 & 0.010 \\
\hline Lt Knee FX TQ/BW (Nm) & $68.31 \pm 21.38$ & $83.31 \pm 21.38$ & $69.32 \pm 14.32$ & $78.51 \pm 15.13$ & $70.35 \pm 16.23$ & $70.76 \pm 26.02$ & 0.802 & 0.000 & 0.000 \\
\hline Lt. ankle $\mathrm{PF}\left({ }^{\circ}\right)$ & $51.26 \pm 3.87$ & $53.30 \pm 3.80$ & $51.34 \pm 4.16$ & $52.20 \pm 4.13$ & $51.19 \pm 5.46$ & $51.10 \pm 4.95$ & 0.848 & 0.000 & 0.000 \\
\hline Lt. ankle DF $\left(^{\circ}\right)$ & $19.40 \pm 1.50$ & $20.66 \pm 1.50$ & $19.96 \pm 1.62$ & $20.33 \pm 1.63$ & $19.91 \pm 2.12$ & $19.85 \pm 1.98$ & 0.862 & 0.000 & 0.000 \\
\hline Rt. ankle $\mathrm{PF}\left({ }^{\circ}\right)$ & $51.26 \pm 3.86$ & $53.14 \pm 3.87$ & $51.34 \pm 5.32$ & $52.13 \pm 5.25$ & $51.19 \pm 5.96$ & $51.48 \pm 5.29$ & 0.927 & 0.000 & 0.012 \\
\hline Rt. ankle DF $\left(^{\circ}\right)$ & $19.94 \pm 1.50$ & $20.70 \pm 1.70$ & $19.96 \pm 2.07$ & $20.20 \pm 2.04$ & $19.91 \pm 2.32$ & $19.90 \pm 2.33$ & 0.899 & 0.000 & 0.002 \\
\hline
\end{tabular}

Values are presented as mean \pm standard deviation.

RI, resistance and interval; RA, resistance and aerobic; Rt Knee EX TQ/BW, right knee-extensor peak torque/body weight; Lt knee EX TQ/BW, left knee-extensor peak torque/ body weight; Rt Knee FX TQ/BW, right knee-flexion peak torque/body weight; Lt Knee FX TQ/BW, Left knee-flexion peak torque/body weight; Lt, left; Rt, right; PF, plantar flexion; $\mathrm{DF}$, dorsal flexion.

time and no interaction effect was found. For the knee isokinetic muscle functions, the RI and RA groups had their right and left extensor strength increased in the posttest $(P<0.001$ each), and interaction effects were found $(P<0.001$ each).

Right and left hamstring strengths increased in the posttest $(P<$ 0.001 each) and interaction effects were found $(P<0.001$ each). For the ankle range of motion, both the RI and RA groups had their right and left dorsal flexion increased in the posttest $(P<0.001$ each) and interaction effects were found $(P<0.001$ each). Both the $\mathrm{RI}$ and RA groups had their right and left plantar flexion increased in the posttest $(P<0.001$ each), with interaction effects being found $(P<0.001$ each $)$.

\section{Changes in functional fitness}

The changes in functional fitness by exercise type are presented in Table 5. Grip differed insignificantly among the groups at each point of time and no interaction effect was found. Both the RI and RA groups had their arm strength increased in the posttest $(P<$ 0.001) and interaction effects were found $(P<0.05)$. Both the RI and RA groups had their leg strength increased in the posttest $(P<$ $0.001)$ and interaction effects were found $(P<0.05)$. Both the RI and RA groups had their 2-min step increased in the posttest $(P<$ 0.001) and no interaction effect was found.

Both the RI and RA groups had their upper limb flexibility improved in the posttest $(P<0.05)$ and interaction effects were found $(P<0.05)$. Lower limb flexibility differed insignificantly among the groups at each point of time and no interaction effect was found.

Functional reach or single-leg stance with eyes closed differed insignificantly among the groups at each point of time and no in- 
Table 5. Change in functional fitness

\begin{tabular}{|c|c|c|c|c|c|c|c|c|c|}
\hline \multirow{2}{*}{ Variable } & \multicolumn{2}{|c|}{ Rl group } & \multicolumn{2}{|c|}{ RA group } & \multicolumn{2}{|c|}{ Control group } & \multicolumn{3}{|c|}{$P$-value } \\
\hline & Pre & Post & Pre & Post & Pre & Post & group & time & Interaction \\
\hline Grip strength (kg) & $24.39 \pm 4.63$ & $24.76 \pm 4.36$ & $24.66 \pm 4.19$ & $24.84 \pm 4.79$ & $24.26 \pm 3.09$ & $24.69 \pm 2.39$ & 0.987 & 0.324 & 0.948 \\
\hline Arm curl (reps/30 sec) & $21.90 \pm 3.60$ & $27.80 \pm 3.58$ & $22.10 \pm 5.34$ & $26.10 \pm 3.81$ & $22.40 \pm 3.60$ & $23.10 \pm 1.45$ & 0.315 & 0.000 & 0.036 \\
\hline Chair stand (reps/30 sec) & $22.30 \pm 3.80$ & $27.10 \pm 3.38$ & $21.90 \pm 3.75$ & $25.30 \pm 3.53$ & $22.30 \pm 5.68$ & $23.80 \pm 4.47$ & 0.643 & 0.000 & 0.029 \\
\hline 2-Min step (reps) & $123.40 \pm 11.41$ & $134.90 \pm 10.19$ & $122.8 \pm 17.57$ & $133.00 \pm 7.86$ & $123.00 \pm 11.56$ & $126.30 \pm 13.50$ & 0.650 & 0.000 & 0.219 \\
\hline Chair sit \& reach $(\mathrm{cm})$ & $20.67 \pm 8.21$ & $26.48 \pm 7.45$ & $21.38 \pm 5.65$ & $25.50 \pm 5.42$ & $21.33 \pm 7.63$ & $21.26 \pm 6.40$ & 0.688 & 0.000 & 0.010 \\
\hline Back scratch (cm) & $6.10 \pm 9.01$ & $5.05 \pm 9.00$ & $5.70 \pm 7.03$ & $4.35 \pm 6.52$ & $5.30 \pm 8.00$ & $5.65 \pm 8.65$ & 0.987 & 0.023 & 0.048 \\
\hline Functional reach $(\mathrm{cm})$ & $22.50 \pm 3.09$ & $24.54 \pm 1.99$ & $21.50 \pm 4.22$ & $22.29 \pm 3.80$ & $23.93 \pm 4.17$ & $24.49 \pm 4.02$ & 0.225 & 0.146 & 0.693 \\
\hline One-leg stance (sec) & $11.23 \pm 10.59$ & $11.49 \pm 6.55$ & $11.04 \pm 11.31$ & $11.30 \pm 2.70$ & $10.61 \pm 3.16$ & $10.78 \pm 2.51$ & 0.966 & 0.880 & 1.000 \\
\hline 2.45-m up-and-go (sec) & $3.99 \pm 0.73$ & $3.09 \pm 0.60$ & $3.97 \pm 0.56$ & $3.47 \pm 0.35$ & $3.83 \pm 0.28$ & $3.91 \pm 0.37$ & 0.270 & 0.000 & 0.000 \\
\hline
\end{tabular}

Values are presented as mean \pm standard deviation.

$\mathrm{Rl}$, resistance and interval; RA, resistance and aerobic.

Table 6. Change in cognitive function

\begin{tabular}{|c|c|c|c|c|c|c|c|c|c|}
\hline \multirow{2}{*}{ Variable } & \multicolumn{2}{|c|}{ Rl group } & \multicolumn{2}{|c|}{ RA group } & \multicolumn{2}{|c|}{ Control group } & \multicolumn{3}{|c|}{$P$-value } \\
\hline & Pre & Post & Pre & Post & Pre & Post & Group & Time & Interaction \\
\hline Memory ability (score) & $2.40 \pm 1.96$ & $2.80 \pm 1.69$ & $2.50 \pm 1.27$ & $2.60 \pm 1.17$ & $2.90 \pm 1.10$ & $2.70 \pm 1.34$ & 0.907 & 0.634 & 0.507 \\
\hline Language ability (score) & $2.20 \pm 1.03$ & $1.60 \pm 1.08$ & $2.00 \pm 1.49$ & $1.50 \pm 0.97$ & $1.50 \pm 1.72$ & $1.80 \pm 0.92$ & 0.832 & 0.382 & 0.418 \\
\hline Daily living ability (score) & $0.30 \pm 0.48$ & $0.30 \pm 0.48$ & $0.00 \pm 0.00$ & $0.10 \pm 0.32$ & $0.20 \pm 0.42$ & $0.30 \pm 0.68$ & 0.220 & 0.550 & 0.913 \\
\hline Total (score) & $4.90 \pm 2.51$ & $4.70 \pm 2.35$ & $4.50 \pm 2.59$ & $4.20 \pm 1.62$ & $4.60 \pm 2.46$ & $4.80 \pm 2.04$ & 0.867 & 0.815 & 0.879 \\
\hline
\end{tabular}

Values are presented as mean \pm standard deviation.

$\mathrm{Rl}$, resistance and interval; RA, resistance and aerobic.

Table 7. Change in sleep quality

\begin{tabular}{|c|c|c|c|c|c|c|c|c|c|}
\hline \multirow{2}{*}{ Variable } & \multicolumn{2}{|c|}{ Rl group } & \multicolumn{2}{|c|}{ RA group } & \multicolumn{2}{|c|}{ Control group } & \multicolumn{3}{|c|}{$P$-value } \\
\hline & Pre & Post & Pre & Post & Pre & Post & Group & Time & Interaction \\
\hline Subjective sleep quality (score) & $1.80 \pm 0.42$ & $1.80 \pm 0.42$ & $2.00 \pm 0.47$ & $1.90 \pm 0.57$ & $2.30 \pm 0.95$ & $2.30 \pm 0.95$ & 0.229 & 0.582 & 0.736 \\
\hline Sleep latency (score) & $2.10 \pm 0.57$ & $1.80 \pm 0.63$ & $1.70 \pm 0.95$ & $1.30 \pm 0.67$ & $1.70 \pm 0.82$ & $1.70 \pm 0.82$ & 0.371 & 0.031 & 0.270 \\
\hline Sleep duration (score) & $1.00 \pm 0.94$ & $0.80 \pm 0.79$ & $0.70 \pm 1.16$ & $0.70 \pm 1.16$ & $0.90 \pm 0.74$ & $0.90 \pm 0.74$ & 0.858 & 0.145 & 0.125 \\
\hline Habitual sleep efficiency (score) & $0.70 \pm 0.67$ & $0.50 \pm 0.71$ & $0.40 \pm 0.97$ & $0.40 \pm 0.97$ & $0.40 \pm 0.97$ & $0.40 \pm 0.97$ & 0.841 & 0.145 & 0.125 \\
\hline Sleep disturbances (score) & $2.10 \pm 0.74$ & $2.00 \pm 0.82$ & $2.10 \pm 0.32$ & $1.90 \pm 0.57$ & $2.20 \pm 0.63$ & $2.20 \pm 0.63$ & 0.707 & 0.388 & 0.775 \\
\hline Use of sleeping medication (score) & $1.30 \pm 0.67$ & $1.00 \pm 0.00$ & $1.10 \pm 0.32$ & $1.10 \pm 0.32$ & $1.00 \pm 0.00$ & $1.00 \pm 0.00$ & 0.452 & 0.171 & 0.158 \\
\hline Day time dysfunction (score) & $1.60 \pm 0.52$ & $1.30 \pm 0.48$ & $1.30 \pm 0.48$ & $1.30 \pm 0.48$ & $1.40 \pm 0.84$ & $1.40 \pm 0.84$ & 0.858 & 0.060 & 0.034 \\
\hline Total (score) & $10.60 \pm 1.17$ & $9.20 \pm 2.04$ & $9.30 \pm 2.31$ & $8.60 \pm 2.55$ & $9.90 \pm 3.45$ & $9.90 \pm 3.57$ & 0.645 & 0.001 & 0.014 \\
\hline
\end{tabular}

Values are presented as mean \pm standard deviation.

$\mathrm{Rl}$, resistance and interval; RA, resistance and aerobic.

teraction effect was found. Both the RI and RA groups had a $2.45 \mathrm{~m}$ decrease in the posttest $(P<0.001)$, with interaction effects found $(P<0.001)$.

\section{Changes in cognitive functions}

As for the changes in the cognitive function by exercise type, memory, linguistic competence, or activities of daily living differed insignificantly among the groups at each point of time, as presented in Table 6, and no interaction effect was found.

\section{Changes in quality of sleep}

The changes in the quality of sleep by exercise type are presented in Table 7. The quality of sleep, sleep duration, usual sleep efficiency, sleep disturbance, or sleeping medication use differed insignificantly among the groups at each point of time and no interaction effect was found. In contrast, sleep latency differed signifi- 
cantly at each point of time $(P<0.05)$ and no interaction effect was found. While daytime dysfunction differed insignificantly at each point of time, interaction effects were found $(P<0.05)$. Both the RI and RA groups scored higher for their quality of sleep in general in the posttest compared with the pretest $(P<0.01)$, with interaction effects found $(P<0.05)$.

\section{DISCUSSION}

Exercise program composition is essential for disability-adjusted life expectancy of the elderly. While aerobic exercise was primarily recommended in the past, importance is also attached to resistance exercise. Recently, the interval training of alternatively repeating low- and high-intensity exercise as a new paradigm to enhancing performance among athletes has been recommended for the health promotion in the elderly population. This study is composed of 12 weeks combined exercise for elderly women and is aimed to determine the effects of RIT and RAE on the visceral fat to skeletal muscle area ratio, physical fitness, cognitive functions, and quality of sleep. Both RIT and RAE were effective in changing the visceral fat to skeletal muscle area ratio, IGF-1, knee isokinetic muscle functions, ankle range of motion, functional fitness, and quality of sleep. However, no difference was found between the two types of exercise.

One of the main factors interfering with independent life in old age is sarcopenia. Sarcopenia means a decrease in skeletal muscle mass due to the decrease in the number of muscle fiber and the transversal area of muscle. This is caused by the decrease in hormone affecting muscle protein synthesis and body activity deficiency (Fielding et al., 2011; Møller et al., 2007). Exercise is key to sarcopenia prevention for the elderly (Visvanathan and Chapman, 2010). As results of this study, neither RIT nor RAE significantly changed the body fat percentage or the metabolic syndrome risk factors. The $\mathrm{CT}$ scan found no decrease in the visceral fat area but verified effectiveness in increasing the thigh skeletal muscle area. This result is similar to the finding that resistance exercise and interval training increased the transversal area of muscle and skeletal muscle mass (Bell et al., 2015; Roth et al., 2001). However, no significant difference was found in the growth hormone or testosterone, any of which decreases with aging. In contrast, IGF-1, which is a usual index of growth hormone excretion and causes protein synthesis and skeletal muscle hypertrophy, increased significantly. The literature review found contradicting results regarding skeletal muscle mass and aging-related hormone of the elderly by exercise type and intensity (Consitt et al., 2002). There- fore, further research should be conducted on exercise intensity and volume that are effective in promoting muscle protein synthesis between the two types of exercise.

Also, sarcopenia reduces the ability to perform physical activities that are important for the elderly in daily life. As results of this study, neither RIT nor RAE made significant differences in $\mathrm{VO}_{2 \max }$, which is an index of cardiorespiratory fitness. However, these types of exercise were effective in improving knee joint muscle strength, which is used as a criterion for muscle strength measurement, and the ankle range of motion, which affects gait in the elderly population. This result is partially consistent with the finding that a mix of aerobic and resistance exercise as interval training improves oxygen uptake and knee joint muscle strength in the elderly population (Verney et al., 2006). They were also effective in improving arm and leg strength, 2-min step, upper limb flexibility, and 2.45-m up-and-go among the subareas of functional fitness considered important for daily living in the elderly population. Villanueva et al. (2015) also reported that high-intensity interval training increased arm and leg strength which is considered important among the elements of physical fitness for the elderly. Other researchers found that aerobic and resistance exercises were effective in improving functional fitness (Liu and Latham, 2009; Roma et al., 2013). Therefore, it can be said that a combined type of exercise, which is composed of resistance exercise, followed by aerobic exercise or interval training, is an effective intervention in improving the physical fitness necessary for the elderly to independently lead their daily lives.

Aging causes cognitive malfunction. These cognitive functions include memory and learning, concentration, perception, reasoning, and problem-solving. It is known that exercise increases the cerebral blood flow, brain-derived neurotrophic factor concentration and prevents cognitive malfunction (Cotman and Berchtold, 2002; Hall et al., 2001). As a result of this study, no significant difference was found in the changes of the cognitive functions between RAT and RAE. However, many researchers confirmed that aerobic and resistance exercises were effective in improving the cognitive functions (Cassilhas et al., 2007; Colcombe et al., 2006; Liu-Ambrose et al., 2010). The cognitive function test in this study is for screening. Therefore, research should be conducted to demonstrate the effectiveness of resistance exercise and interval training in objectively improving cognitive functions.

In old age, the disturbance of daily bio-rhythm affecting sleep and awakening can result in sleep disturbance. Sleep disturbance involves various symptoms, including troubled sleep maintenance, frequent awakening, frequent sleeping medication use, and excessive daytime drowsiness. Exercise and physical activity promotion 
are recommended for a higher quality of sleep (Shirota et al., 2000; Uezu et al., 2000). This study found that RAT and RAE were effective in changing the quality of sleep. De Jong et al. (2006) also found that sports activity improved the perceived quality of sleep for seniors with sedentary lifestyle. It can be said, therefore, that every type of exercise in this study is effective in improving the quality of sleep, which contributes to the recovery of physical and mental functions in the elderly population.

In conclusion, RAT and RAE were effective in improving the physical fitness and quality of sleep by increasing the skeletal muscle area and IGF-1 in old women. However, no difference was found between interval training and aerobic exercise, which followed resistance exercise. Further research should be conducted, taking into account intergroup variation in exercise intensity, exercise volume, and dietary intake influencing muscle protein synthesis, in a larger population.

\section{CONFLICT OF INTEREST}

No potential conflict of interest relevant to this article was reported.

\section{ACKNOWLEDGMENTS}

This work was supported by the National Research Foundation of Korea (NRF) grant funded by the Korea government (2018S1A5A2A01030746).

\section{REFERENCES}

Bell KE, Séguin C, Parise G, Baker SK, Phillips SM. Day-to-day changes in muscle protein synthesis in recovery from resistance, aerobic, and highintensity interval exercise in older men. J Gerontol A Biol Sci Med Sci 2015;70:1024-1029.

Buysse DJ, Reynolds CF 3rd, Monk TH, Berman SR, Kupfer DJ. The Pittsburgh Sleep Quality Index: a new instrument for psychiatric practice and research. Psychiatry Res 1989;28:193-213.

Cassilhas RC, Viana VA, Grassmann V, Santos RT, Santos RF, Tufik S, Mello MT. The impact of resistance exercise on the cognitive function of the elderly. Med Sci Sports Exerc 2007;39:1401-1407.

Colcombe SJ, Erickson KI, Scalf PE, Kim JS, Prakash R, McAuley E, Elavsky S, Marquez DX, Hu L, Kramer AF. Aerobic exercise training increases brain volume in aging humans. J Gerontol A Biol Sci Med Sci 2006;61: 1166-1170.

Consitt LA, Copeland JL, Tremblay MS. Endogenous anabolic hormone responses to endurance versus resistance exercise and training in women. Sports Med 2002;32:1-22.

Cotman CW, Berchtold NC. Exercise: a behavioral intervention to enhance brain health and plasticity. Trends Neurosci 2002;25:295-301.

Crowley K. Sleep and sleep disorders in older adults. Neuropsychol Rev 2011;21:41-53.

De Jong J, Lemmink KA, Stevens M, de Greef MH, Rispens P, King AC, Mulder T. Six-month effects of the Groningen active living model (GALM) on physical activity, health and fitness outcomes in sedentary and underactive older adults aged 55-65. Patient Educ Couns 2006;62: 132-141.

Enoki H, Kuzuya M, Masuda Y, Hirakawa Y, Iwata M, Hasegawa J, Izawa S, Iguchi A. Anthropometric measurements of mid-upper arm as a mortality predictor for community-dwelling Japanese elderly: the Nagoya Longitudinal Study of Frail Elderly (NLS-FE). Clin Nutr 2007;26: 597-604.

Fielding RA, Vellas B, Evans WJ, Bhasin S, Morley JE, Newman AB, Abellan van Kan G, Andrieu S, Bauer J, Breuille D, Cederholm T, Chandler J, De Meynard C, Donini L, Harris T, Kannt A, Keime Guibert F, Onder G, Papanicolaou D, Rolland Y, Rooks D, Sieber C, Souhami E, Verlaan S, Zamboni M. Sarcopenia: an undiagnosed condition in older adults. Current consensus definition: prevalence, etiology, and consequences. International working group on sarcopenia. J Am Med Dir Assoc 2011; 12:249-256.

Fleck SJ, Kraemer WJ. Resistance training: Basic principles (Part 1 of 4). Phys Sportsmed 1988;16:160-171.

Foley DJ, Monjan AA, Brown SL, Simonsick EM, Wallace RB, Blazer DG. Sleep complaints among elderly persons: an epidemiologic study of three communities. Sleep 1995;18:425-432.

Gibala MJ, Jones AM. Physiological and performance adaptations to highintensity interval training. Nestle Nutr Inst Workshop Ser 2013;76: 51-60.

Hagberg JM, Graves JE, Limacher M, Woods DR, Leggett SH, Cononie C, Gruber JJ, Pollock ML. Cardiovascular responses of 70- to 79-yr-old men and women to exercise training. J Appl Physiol (1985) 1989;66: 2589-2594.

Haimov I, Hanuka E, Horowitz Y. Chronic insomnia and cognitive functioning among older adults. Behav Sleep Med 2008;6:32-54.

Hall CD, Smith AL, Keele SW. The impact of aerobic activity on cognitive function in older adults: a new synthesis based on the concept of executive control. Eur J Cogn Psychol 2001;13:279-300.

Janssen I, Heymsfield SB, Ross R. Low relative skeletal muscle mass (sarcopenia) in older persons is associated with functional impairment and physical disability. J Am Geriatr Soc 2002;50:889-896.

Karvonen MJ, Kentala E, Mustala O. The effects of training on heart rate; 
a longitudinal study. Ann Med Exp Biol Fenn 1957;35:307-315.

Koopman R, van Loon LJ. Aging, exercise, and muscle protein metabolism. J Appl Physiol (1985) 2009;106:2040-2048.

Liu CJ, Latham NK. Progressive resistance strength training for improving physical function in older adults. Cochrane Database Syst Rev 2009; (3):CD002759.

Liu-Ambrose T, Nagamatsu LS, Graf P, Beattie BL, Ashe MC, Handy TC. Resistance training and executive functions: a 12-month randomized controlled trial. Arch Intern Med 2010;170:170-178.

Luck T, Luppa M, Briel S, Matschinger H, König HH, Bleich S, Villringer A, Angermeyer MC, Riedel-Heller SG. Mild cognitive impairment: incidence and risk factors: results of the leipzig longitudinal study of the aged. J Am Geriatr Soc 2010;58:1903-1910.

Milanović Z, Sporiš G, Weston M. Effectiveness of high-intensity interval training (HIT) and continuous endurance training for $\mathrm{VO}_{2 \max }$ improvements: a systematic review and meta-analysis of controlled trials. Sports Med 2015;45:1469-1481.

Misic MM, Rosengren KS, Woods JA, Evans EM. Muscle quality, aerobic fitness and fat mass predict lower-extremity physical function in community-dwelling older adults. Gerontology 2007;53:260-266.

Møller N, Copeland KC, Nair KS. Growth hormone effects on protein metabolism. Endocrinol Metab Clin North Am 2007;36:89-100.

Nair KS. Aging muscle. Am J Clin Nutr 2005;81:953-963.

Ramírez-Campillo R, Castillo A, de la Fuente CI, Campos-Jara C, Andrade DC, Álvarez C, Martínez C, Castro-Sepúlveda M, Pereira A, Marques $\mathrm{MC}$, Izquierdo M. High-speed resistance training is more effective than low-speed resistance training to increase functional capacity and muscle performance in older women. Exp Gerontol 2014;58:51-57.

Robinson MM, Dasari S, Konopka AR, Johnson ML, Manjunatha S, Esponda RR, Carter RE, Lanza IR, Nair KS. Enhanced protein translation underlies improved metabolic and physical adaptations to different exercise training modes in young and old humans. Cell Metab 2017;25:581-592.

Rognmo Ø, Hetland E, Helgerud J, Hoff J, Slørdahl SA. High intensity aerobic interval exercise is superior to moderate intensity exercise for increasing aerobic capacity in patients with coronary artery disease. Eur J Cardiovasc Prev Rehabil 2004;11:216-222.

Rolland Y, Czerwinski S, Abellan Van Kan G, Morley JE, Cesari M, Onder G, Woo J, Baumgartner R, Pillard F, Boirie Y, Chumlea WM, Vellas B. Sarcopenia: its assessment, etiology, pathogenesis, consequences and future perspectives. J Nutr Health Aging 2008;12:433-450.

Roma MF, Busse AL, Betoni RA, Melo AC, Kong J, Santarem JM, Jacob
Filho W. Effects of resistance training and aerobic exercise in elderly people concerning physical fitness and ability: a prospective clinical trial. Einstein (Sao Paulo) 2013;11:153-157.

Roth SM, Martel GF, Ivey FM, Lemmer JT, Tracy BL, Metter EJ, Hurley $\mathrm{BF}$, Rogers MA. Skeletal muscle satellite cell characteristics in young and older men and women after heavy resistance strength training. J Gerontol A Biol Sci Med Sci 2001;56:B240-247.

Rowe JW, Kahn RL. Successful aging. Gerontologist 1997;37:433-440.

Shirota A, Tamaki M, Hayashi M, Hori T. Effects of daytime activity on nocturnal sleep in the elderly. Psychiatry Clin Neurosci 2000;54:309310.

Short KR, Vittone JL, Bigelow ML, Proctor DN, Nair KS. Age and aerobic exercise training effects on whole body and muscle protein metabolism. Am J Physiol Endocrinol Metab 2004;286:E92-101.

Sohn SI, Kim DH, Lee MY, Cho YW. The reliability and validity of the Korean version of the Pittsburgh Sleep Quality Index. Sleep Breath 2012;16:803-812.

Strasser B, Keinrad M, Haber P, Schobersberger W. Efficacy of systematic endurance and resistance training on muscle strength and endurance performance in elderly adults-a randomized controlled trial. Wien Klin Wochenschr 2009;121:757-764.

Uezu E, Taira K, Tanaka H, Arakawa M, Urasakii C, Toguchi H, Yamamoto Y, Hamakawa E, Shirakawa S. Survey of sleep-health and lifestyle of the elderly in Okinawa. Psychiatry Clin Neurosci 2000;54:311313.

Verney J, Kadi F, Saafi MA, Piehl-Aulin K, Denis C. Combined lower body endurance and upper body resistance training improves performance and health parameters in healthy active elderly. Eur J Appl Physiol 2006;97:288-297.

Villanueva MG, Lane CJ, Schroeder ET. Short rest interval lengths between sets optimally enhance body composition and performance with 8 weeks of strength resistance training in older men. Eur J Appl Physiol 2015;115:295-308.

Visvanathan R, Chapman I. Preventing sarcopaenia in older people. Maturitas 2010;66:383-388.

Weston M, Taylor KL, Batterham AM, Hopkins WG. Effects of low-volume high-intensity interval training (HIT) on fitness in adults: a meta-analysis of controlled and non-controlled trials. Sports Med 2014;44: 1005-1017.

Yang DW, Cho B, Chey JY, Kim SY, Kim BS. The development and validation of Korean Dementia Screening Questionnaire (KDSQ). J Korean Neurol Assoc 2002;20:1-8. 